Article

\title{
Simple Power Quality Compensation with Bidirectional Battery Charger for Electric Vehicles in Single-Phase Three-Wire Distribution Feeders
}

\author{
Fuka Ikeda ${ }^{1, *, \dagger}$, Kei Nishikawa ${ }^{2, \dagger}$, Yuki Okamoto ${ }^{2, \dagger}$, Hiroaki Yamada ${ }^{2,+} \oplus$, Toshihiko Tanaka ${ }^{2, \dagger}$ \\ and Masayuki Okamoto ${ }^{1,+}$ \\ 1 Department of Electrical Engineering, National Institute of Technology, Ube College, 2-14-1 Tokiwadai, Ube, \\ Yamaguchi 755-8555, Japan; mokamoto@ube-k.ac.jp \\ 2 Department of Electrical and Electronic Engineering, Yamaguchi University, 2-16-1 Tokiwadai, Ube, \\ Yamaguchi 755-8611, Japan; g004wc@yamaguchi-u.ac.jp (K.N.); g025vg@yamaguchi-u.ac.jp (Y.O.); \\ hiro-ymd@yamaguchi-u.ac.jp (H.Y.); totanaka@yamaguchi-u.ac.jp (T.T.) \\ * Correspondence: fikeda@ube-k.ac.jp; Tel.: +81-836-31-6111 \\ + These authors contributed equally to this work.
}

Received: 13 March 2020; Accepted: 29 May 2020; Published: 5 June 2020

\begin{abstract}
This paper deals with power quality compensation in single-phase three-wire distribution feeders using a constant DC-capacitor voltage-control (CDCVC)-based strategy of the previously proposed bidirectional battery charger (BBC) for electric vehicles under the distorted source-voltage and load-current conditions. Instantaneous active power flowing into the three-leg pulse-width-modulated (PWM) rectifier in the BBC is discussed. The instantaneous power flowing into the three-leg PWM rectifier demonstrates that the CDCVC-based strategy obtains balanced and sinusoidal source currents at a unity power factor, where the source-side active power is balanced with the load-side active power. Simulation and experimental results demonstrate that balanced and sinusoidal source currents at a unity power factor are attained in single-phase three-wire distribution feeders with both battery-charging and -discharging operations for electric vehicles even though both source voltage and load currents are distorted.
\end{abstract}

Keywords: bidirectional battery; three-leg PWM rectifier; bidirectional dc-dc converter; single-phase three-wire distribution feeders; constant dc-capacitor voltage-control-based harmonics compensation

\section{Introduction}

Electric vehicles (EVs) are nowadays commercially available by several makers worldwide. A large amount of electric power can be stored in lithium-ion batteries of EVs. The stored electric power can be injected into the utility-grid; this is named as vehicle-to-grid (V2G). A domestic consumer can consume the stored electric energy, where the lithium-ion batteries in an EV perform as a peak shaver; this is called vehicle-to-home (V2H). These interesting concepts were proposed in [1-6]. A bidirectional battery charger (BBC) using three-leg-structured isolated-gate bipolar transistors (IGBTs), which consists of a single-phase two-leg pulse-width-modulated (PWM) rectifier and a bidirectional DC-DC converter, is used in V2G and V2H. In [7], the vehicle-to-vehicle (V2V) concept was proposed in addition to $\mathrm{V} 2 \mathrm{G}$ and $\mathrm{V} 2 \mathrm{H}$. It is well known that the reactive and harmonic currents can be controlled independently of the fundamental active currents on the source side [8]. Therefore, reactive power compensation strategy was included in the control circuit of the single-phase two-leg PWM rectifier in the BBC to control the source-side terminal voltage at the point of common coupling in single-phase two-wire distribution feeders [9-12]. For three-phase circuits, G. Buja et al. dealt with reactive power compensation capabilities with V2G [13]. 
Single-phase three-wire distribution feeders are used for domestic consumers in Japan. When the two-leg PWM rectifier with reactive power control is used to control the source-side terminal voltage at the point of common coupling in single-phase three-wire distribution feeders, unbalanced source-side current conditions remain. The present authors proposed a BBC with a power quality compensator for EVs, which was applicable to a domestic consumer in single-phase three-wire distribution feeders [14]. The previously proposed BBC comprises four-leg-structured IGBTs. Two legs connect each feeder, while one leg connects a neutral line. Connecting one leg to the neutral line can compensate the unbalanced components in single-phase three-wire distribution feeders. The fourth leg is used as a bidirectional DC-DC converter. This bidirectional DC-DC converter charges or discharges the lithium-ion batteries in EVs. A constant DC-capacitor voltage control (CDCVC)-based strategy was used for the control algorithm of the three-leg PWM rectifier in the previously proposed BBC. Simulation and experimental results demonstrated that the three-leg PWM rectifier in the previously proposed BBC achieved the balanced source currents at a unity power factor. Diode rectifiers with large-capacity smoothing capacitors are widely used in consumer electronics nowadays. These diode rectifiers, however, generate a large amount of harmonic currents and inject them into utility-grid. Therefore, the authors dealt with power quality compensation of the CDCVC-based control algorithm for the previously proposed BBC [15]. Simulation and experimental results demonstrated that the balanced and sinusoidal source currents at a unity power factor were obtained in the domestic consumers, which are connected to single-phase three-wire distribution feeders. Works in literature [14,15] demonstrated that the CDCVC-based strategy for the three-leg PWM rectifier in the BBC can compensate not only the fundamental reactive and unbalanced active components but also harmonic components on the source side of the domestic consumers in single-phase three-wire distribution feeders. However, the source-side terminal voltages at the point of common coupling in single-phase three-wire distribution feeders were sinusoidal. It is also known that the diode rectifier with the large-capacity smoothing capacitor produces flat-top voltage waveforms at the point of common coupling in single-phase distribution feeders [16]. These flat-top voltage waveforms are typical in single-phase distribution feeders. The definition of the flat-top voltage waveform is described in detail [17]. According to the IEEE Standard 519-2014 [18], the maximum total harmonic distortion (THD) value of the voltage at the point of common coupling is determined to be $5.0 \%$, and the ratios of each individual-order harmonics to the fundamental component should be less than $3.0 \%$ if the bus voltage is from $1 \mathrm{kVrms}$ to $69 \mathrm{kVrms}$. Therefore, not only distorted load-current but also distorted source-voltage with the flat-top voltage waveforms should be taken into account if the previously proposed BBC is connected to actual domestic consumers in single-phase three-wire distribution feeders. In [15], the load-side currents in a domestic consumer were distorted while the source-side voltage was sinusoidal. This means that only the fundamental active power is included in the load currents. The fundamental active power also exists on the source side, before or after compensating the power quality on the source side by the three-leg PWM rectifier in the BBC. This demonstrates that the source-side fundamental active power equals the load-side fundamental active power. However, the harmonic active power in addition to the fundamental active power exists on the load side when both the terminal voltages at the point of common coupling and load currents in a domestic consumer are distorted. Only the fundamental active power exists on the source side after compensating the power quality in the domestic consumer by the three-leg PWM rectifier in the BBC. Therefore, balancing of the source-side active power with the load-side active power by CDCVC-based strategy for the three-leg PWM rectifier in the BBC should be demonstrated.

This paper deals with power quality compensation in single-phase three-wire distribution feeders using the CDCVC-based strategy of the previously proposed BBC for electric vehicles under the distorted source-voltage and load-current conditions. Instantaneous active power flowing into the three-leg PWM rectifier in the BBC is discussed. The instantaneous power flowing into the three-leg PWM rectifier demonstrates that the CDCVC-based strategy obtains balanced and sinusoidal source currents at a unity power factor, where the source-side fundamental active power is balanced with the load-side active power, which consists of the harmonic active power in addition to the fundamental 
active power. Simulation and experimental results demonstrate that balanced and sinusoidal source currents at a unity power factor are attained in single-phase three-wire distribution feeders with both battery-charging and -discharging operations for electric vehicles even though both source voltage and load currents are distorted.

\section{Power Quality Compensation in Single-Phase Three-Wire Distribution Feeders with CDCVC-Based Strategy of BBC under Distorted Source-Voltage and Load-Current Conditions}

Figure 1 shows a circuit diagram of the previously proposed BBC in single-phase three-wire distribution feeders, where both secondary-side voltages $v_{\mathrm{L} 1}$ and $v_{\mathrm{L} 2}$ and load currents $i_{\mathrm{L} 1}$ and $i_{\mathrm{L} 2}$ are distorted. Many consumer electronics nowadays contain diode rectifiers. Thus, diode rectifiers are connected to both feeders. The THD values of the load currents $i_{\mathrm{L} 1}$ and $i_{\mathrm{L} 2}$ were determined considering IEC61000-3-4 [19]. By the IEEE Standard 519-2014, the maximum THD value of the voltage at the point of common coupling is determined to be $5.0 \%$, and the ratios of each individual-order harmonics to the fundamental component should be less than $3.0 \%$ when the bus voltage is from $1 \mathrm{kVrms}$ to $69 \mathrm{kVrms}$ [18]. In Figure 1, the primary-side voltage of the distribution transformer is $6.6 \mathrm{kVrms}$. Thus, the primary-side voltage distortion is decided according to the IEEE Standard 519-2014. The third-order harmonic voltage of $2.7 \%$, fifth-order harmonic voltage of $2.0 \%$, and seventh-order harmonic voltage of $1.2 \%$ are included in the primary-side voltage $v_{S}$ in Figure 1 . Considering these harmonic voltages in the primary-side voltage $v_{\mathrm{S}}$, the flat-top voltage waveforms at the point of common coupling are achieved. The THD value of the source voltage $v_{S}$ on the primary-side is $3.6 \%$. The BBCs for EVs, for which the source-side power quality can be improved, were proposed for V2G and V2H concepts [9-11]. The proposed BBCs comprise a two-leg-structured PWM rectifier with a bidirectional DC-DC converter. However, the proposed BBCs for EVs with power quality compensation proposed in [9-11] are not applicable to single-phase three-wire distribution feeders. A three-leg PWM rectifier is used in Figure 1. Connecting the third-leg $\mathrm{Q}_{5}$ and $\mathrm{Q}_{6}$ to the neutral line can compensate the unbalanced components in single-phase three-wire distribution feeders. Table 1 shows test data for the single-phase distribution transformer used in Figure 1 on PSIM software.
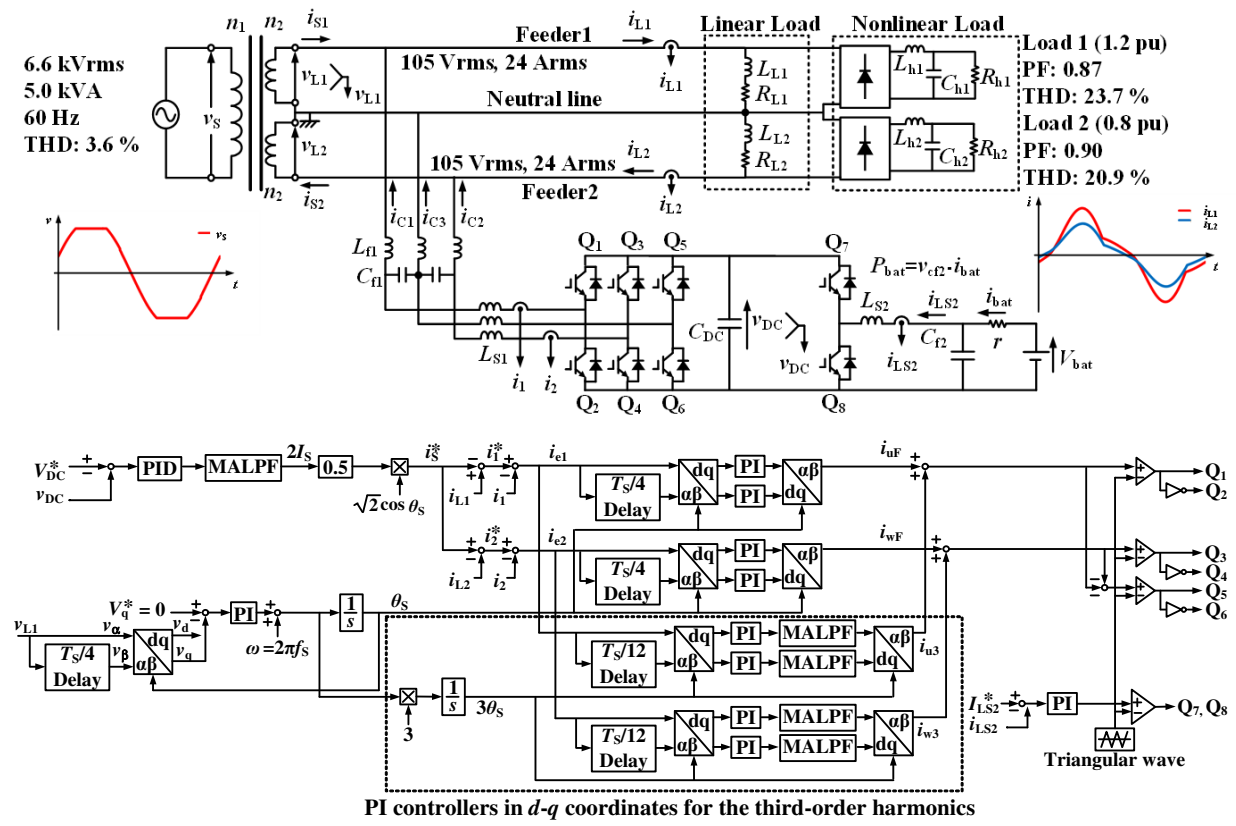

Figure 1. Power circuit diagram with control circuit of bidirectional battery charger (BBC) for electric vehicles (EVs) in single-phase three-wire distribution feeders under distorted source-voltage and load-current conditions. 
Table 1. Test data for single-phase distribution transformer in Figure 1 on PSIM software.

\begin{tabular}{lccc}
\hline & Item & Symbol & Value \\
\hline & Rated voltage & $V_{\mathrm{r}}$ & $6.6 \mathrm{kVrms}$ \\
& Rated power & $S_{\mathrm{r}}$ & $5 \mathrm{kVA}$ \\
\hline \multirow{2}{*}{ Open circuit test } & Open circuit current & $I_{0}$ & $30.3 \mathrm{mArms}$ \\
& Open circuit power & $P_{0}$ & $36.9 \mathrm{~W}$ \\
\hline \multirow{2}{*}{ Short circuit test } & Short circuit voltage & $V_{\mathrm{S}}$ & $164.3 \mathrm{Vrms}$ \\
& Short circuit power & $P_{\mathrm{S}}$ & $103.3 \mathrm{~W}$ \\
\hline
\end{tabular}

For the control algorithm of active power-line conditioners in three-phase circuits, the instantaneous active-reactive power theory, which was originally proposed by Prof. Akagi et al., is widely used [8]. A single-phase p-q theory was also proposed for an active power-line conditioner in single-phase circuits [20]. Calculation blocks for the reactive, unbalanced-active, and harmonic components are required in the control circuits of the active power-line conditioners with those theories. The CDCVC block is also included in addition to the calculation blocks for the unbalanced active, reactive, and harmonic components. In Figure 1 however, only the CDCVC block is used for the control strategy of the three-leg PWM rectifier in the BBC. This CDCVC-based strategy attains balanced and sinusoidal source currents at a unity power factor. The secondary-side voltage $v_{\mathrm{L} 1}$ is detected. The electrical angle $\theta_{\mathrm{S}}$ that is synchronized with $v_{\mathrm{L} 1}$ is then generated by the single-phase phase-locked loop (PLL) [21,22]. Note that the single-phase PLL proposed in $[21,22]$ can generate the angular frequency $\omega_{S}$, which is perfectly synchronized with the fundamental component of $v_{\mathrm{L} 1}$, under the heavily distorted source-voltage conditions. The DC-capacitor voltage $v_{\mathrm{DC}}$ of the three-leg PWM rectifier is detected, and then the difference $\Delta v_{\mathrm{DC}}$ between the reference value $V_{\mathrm{DC}}^{*}$ and the detected $v_{\mathrm{DC}}$ is amplified by the Proportional-Integral-Differential (PID) controller. A moving-average low-pass filter (MALPF) is used to remove the $2 \omega_{\mathrm{S}}$ components, where $\omega_{\mathrm{S}}$ is the angular frequency of $v_{\mathrm{L} 1}$. After the MALPF, the root-mean-square (RMS) value $2 I_{\mathrm{S}}$ of the source currents $i_{S 1}$ and $i_{S 2}$ is calculated. The reference active component $i_{\mathrm{S}}^{*}$ is calculated by multiplying $I_{S}$ with $\sqrt{2} \cos \theta_{\mathrm{S}}$, where $\theta_{\mathrm{S}}=\omega_{\mathrm{S}} t$. The reference values $i_{1}^{*}$ and $i_{2}^{*}$ for the three-leg PWM rectifier are expressed as

$$
\begin{aligned}
& i_{1}^{*}=i_{\mathrm{L} 1}-i_{\mathrm{S}}^{*} \\
& i_{2}^{*}=-i_{\mathrm{L} 2}+i_{\mathrm{S}}^{*} .
\end{aligned}
$$

A current controller for a single-phase PWM rectifier with Proportional-Integral (PI) controllers in $d-q$ coordinates was proposed to suppress a steady-state error [23]. The proposed current controllers for the single-phase three-leg PWM rectifier are used to control the output currents $i_{1}, i_{2}$, and $i_{3}$. In single-phase circuits, the third-order harmonic currents exist. The third-order harmonic currents affected the THD values of the source currents $i_{\mathrm{S} 1}$ and $i_{\mathrm{S} 2}$ in [15]. The present authors proposed the addition of a current controller for third-order harmonic currents with a PI controller in $d-q$ coordinates to suppress these third-order harmonic components in the source currents [24]. The added current controllers suppress the third-order harmonics on the source side. In this paper, the switching frequency $f_{S}$ is $9.36 \mathrm{kHz}$. The number of data points over the cycle of the fundamental frequency is 156. The number of data points for the quarter-cycle-delay block of the fundamental component is 39. The number of data points for the quarter-cycle-delay block of the third-order harmonics is 13 . The current controllers in $d-q$ coordinates for the third-order harmonics are perfectly synchronized with $v_{\mathrm{S}}$.

The fourth leg, $Q_{7}$ and $Q_{8}$, acts as a bidirectional DC-DC converter. During the battery-charging operation, the fourth leg acts a buck chopper, where $\mathrm{Q}_{7}$ controls the inductor current $i_{\text {LS2 }}$ while $\mathrm{Q}_{8}$ is off and only the diode in $\mathrm{Q}_{8}$ is used. For the battery-discharging operation, the fourth leg acts a boost chopper, where $Q_{8}$ controls $i_{\text {LS2 }}$ while $Q_{7}$ is off and the diode in $Q_{7}$ is used. In both the buck and boost operations, $i_{\mathrm{LS} 2}$ is detected. The difference between the reference value $I_{\mathrm{LS} 2}^{*}$ and $i_{\mathrm{LS} 2}$ is amplified by a PI controller; subsequently, with the triangle intersection method, the control signal for $Q_{7}$ or 
$\mathrm{Q}_{8}$ is generated to control the inductor current $i_{\mathrm{LS} 2}$. As a battery model, an ideal DC voltage source of $360 \mathrm{Vdc}$ with an inner resistor $r$ of $72 \mathrm{~m} \Omega$ in PSIM software is also used because the purpose of this paper is to demonstrate harmonic currents compensation with the CDCVC-based strategy of the previously proposed BBC for electric vehicles in single-phase three-wire distribution feeders under distorted load-currents and source-voltage conditions.

The instantaneous power flowing into the three-leg PWM rectifier in the BBC is now discussed under the distorted source-voltage and load-current conditions to demonstrate that the CDCVC-based strategy in Figure 1 attains the balanced and sinusoidal source currents $i_{\mathrm{S} 1}$ and $i_{\mathrm{S} 2}$ at a unity power factor. In the literature [24], the voltages $v_{\mathrm{L} 1}$ and $v_{\mathrm{L} 2}$ on the secondary side of the distribution transformer were sinusoidal. $v_{\mathrm{L} 1}$ and $v_{\mathrm{L} 2}$ were given by

$$
v_{\mathrm{L} 1}=v_{\mathrm{L} 2}=\sqrt{2} V_{\mathrm{LF}} \cos \omega_{\mathrm{S}}
$$

As described before, the flat-top voltage waveforms are typical in single-phase distribution feeders. According to the IEEE Standard 519-2014, harmonic components are included in the source voltage $v_{\mathrm{S}}$, shown in Figure 1 . When the source voltage $v_{\mathrm{S}}$ is distorted, the secondary-side voltages $v_{\mathrm{L} 1}$ and $v_{\mathrm{L} 2}$ are expressed as

$$
v_{\mathrm{L} 1}=v_{\mathrm{L} 2}=\sqrt{2} V_{\mathrm{LF}} \cos \omega_{\mathrm{S}} t+\sqrt{2} \sum_{n=2}^{\infty} V_{\mathrm{L} n} \cos n \omega_{\mathrm{S}} t
$$

The unbalanced and distorted load currents $i_{\mathrm{L} 1}$ and $i_{\mathrm{L} 2}$ in Feeder1 and Feeder 2 are also expressed as

$$
\begin{aligned}
i_{\mathrm{L} 1}= & \sqrt{2} I_{\mathrm{L} 1 \mathrm{~F}} \cos \left(\omega_{\mathrm{S}} t-\phi_{\mathrm{L} 1 \mathrm{~F}}\right) \\
& +\sqrt{2} \sum_{k=2}^{\infty} I_{\mathrm{L} 1 k} \cos \left(k \omega_{\mathrm{S}} t-\phi_{\mathrm{L} 1 k}\right), \\
i_{\mathrm{L} 2}= & \sqrt{2} I_{\mathrm{L} 2 \mathrm{~F}} \cos \left(\omega_{\mathrm{S}} t-\phi_{\mathrm{L} 2 \mathrm{~F}}\right) \\
& +\sqrt{2} \sum_{k=2}^{\infty} I_{\mathrm{L} 2 k} \cos \left(k \omega_{\mathrm{S}} t-\phi_{\mathrm{L} 2 k}\right) .
\end{aligned}
$$

When the three-leg PWM rectifier in the BBC with CDCVC-based strategy attains the balanced and sinusoidal source currents at a unity power factor, the desired source current $i_{\mathrm{S}}^{*}$, which is $i_{\mathrm{S} 1}$ and $i_{\mathrm{S} 2}$, in Feeder1 and Feeder2 is expressed as

$$
\begin{aligned}
i_{\mathrm{S}}^{*} & =i_{\mathrm{S} 1}=i_{\mathrm{S} 2} \\
& =\sqrt{2} I_{\mathrm{S}} \cos \omega_{\mathrm{S}} t
\end{aligned}
$$

where $I_{\mathrm{S}}$ is the RMS value of $i_{\mathrm{S}}^{*}, i_{\mathrm{S} 1}^{*}$, and $i_{\mathrm{S} 2}^{*}$. With (5), the output currents $i_{\mathrm{C} 1}, i_{\mathrm{C} 2}$, and $i_{\mathrm{C} 3}$ of the three-leg PWM rectifier are given by

$$
\begin{aligned}
& i_{\mathrm{C} 1}=i_{\mathrm{L} 1}-i_{\mathrm{S} 1}, \\
& i_{\mathrm{C} 2}=-i_{\mathrm{L} 2}+i_{\mathrm{S} 2} \\
& i_{\mathrm{C} 3}=-\left(i_{\mathrm{C} 1}+i_{\mathrm{C} 2}\right) .
\end{aligned}
$$


The instantaneous power $p_{\text {Rec }}$ flowing into the three-leg PWM rectifier in the BBC is given by

$$
\begin{aligned}
& p_{\text {Rec }}=-v_{\mathrm{L} 1} \cdot i_{\mathrm{C} 1}+v_{\mathrm{L} 2} \cdot i_{\mathrm{C} 2} \\
& =V_{\mathrm{LF}}\left(-I_{\mathrm{L} 1 \mathrm{~F}} \cos \phi_{\mathrm{L} 1 \mathrm{~F}}-I_{\mathrm{L} 2 \mathrm{~F}} \cos \phi_{\mathrm{L} 2 \mathrm{~F}}+2 I_{\mathrm{S}}\right) \\
& +V_{\mathrm{LF}}\left\{\left(-I_{\mathrm{L} 1 \mathrm{~F}} \cos \phi_{\mathrm{L} 1 \mathrm{~F}}-I_{\mathrm{L} 2 \mathrm{~F}} \cos \phi_{\mathrm{L} 2 \mathrm{~F}}\right) \cos 2 \omega_{\mathrm{S}} t\right. \\
& \left.+\left(-I_{\mathrm{L} 1 \mathrm{~F}} \sin \phi_{\mathrm{L} 1 \mathrm{~F}}-I_{\mathrm{L} 2 \mathrm{~F}} \sin \phi_{\mathrm{L} 2 \mathrm{~F}}\right) \sin 2 \omega_{\mathrm{S}} t\right\} \\
& -2 V_{\mathrm{LF}} \sum_{k=2}^{\infty}\left(I_{\mathrm{L} 1 k} \cos \phi_{\mathrm{L} 1 k} \cos \omega_{\mathrm{S}} t \cos k \omega_{\mathrm{S}} t\right. \\
& +I_{\mathrm{L} 2 k} \cos \phi_{\mathrm{L} 2 k} \cos \omega_{\mathrm{S}} t \cos k \omega_{\mathrm{S}} t \\
& +I_{\mathrm{L} 1 k} \sin \phi_{\mathrm{L} 1 k} \cos \omega_{\mathrm{S}} t \sin k \omega_{\mathrm{S}} t \\
& \left.+I_{\mathrm{L} 2 k} \sin \phi_{\mathrm{L} 2 k} \cos \omega_{\mathrm{S}} t \sin k \omega_{\mathrm{S}} t\right) \\
& -2 \sum_{n=2}^{\infty} V_{\mathrm{L} n}\left(I_{\mathrm{L} 1 \mathrm{~F}} \cos \phi_{\mathrm{L} 1 \mathrm{~F}} \cos \omega_{\mathrm{S}} t \cos n \omega_{\mathrm{S}} t\right. \\
& +I_{\mathrm{L} 2 \mathrm{~F}} \cos \phi_{\mathrm{L} 2 \mathrm{~F}} \cos \omega_{\mathrm{S}} t \cos n \omega_{\mathrm{S}} t \\
& -2 I_{\mathrm{S}} \cos \omega_{\mathrm{S}} t \cos n \omega_{\mathrm{S}} t \\
& +I_{\mathrm{L} 1 \mathrm{~F}} \sin \phi_{\mathrm{L} 1 \mathrm{~F}} \sin \omega_{\mathrm{S}} t \cos n \omega_{\mathrm{S}} t \\
& \left.+I_{\mathrm{L} 2 \mathrm{~F}} \sin \phi_{\mathrm{L} 2 \mathrm{~F}} \sin \omega_{\mathrm{S}} t \cos n \omega_{\mathrm{S}} t\right) \\
& -2 \sum_{n=2}^{\infty} V_{\mathrm{L} n} \sum_{k=2}^{\infty}\left(I_{\mathrm{L} 1 k} \cos \phi_{\mathrm{L} 1 k} \cos n \omega_{\mathrm{S}} t \cos k \omega_{\mathrm{S}} t\right. \\
& +I_{\mathrm{L} 2 k} \cos \phi_{\mathrm{L} 2 k} \cos n \omega_{\mathrm{S}} t \cos k \omega_{\mathrm{S}} t \\
& +I_{\mathrm{L} 1 k} \sin \phi_{\mathrm{L} 1 k} \cos n \omega_{\mathrm{S}} t \sin k \omega_{\mathrm{S}} t \\
& \left.+I_{\mathrm{L} 2 k} \sin \phi_{\mathrm{L} 2 k} \cos n \omega_{\mathrm{S}} t \sin k \omega_{\mathrm{S}} t\right) \text {. }
\end{aligned}
$$

The mean value $\bar{p}_{\operatorname{Rec}}$ is given by

$$
\begin{aligned}
\bar{p}_{\mathrm{Rec}}= & V_{\mathrm{LF}}\left(-I_{\mathrm{L} 1 \mathrm{~F}} \cos \phi_{\mathrm{L} 1 \mathrm{~F}}-I_{\mathrm{L} 2 \mathrm{~F}} \cos \phi_{\mathrm{L} 2 \mathrm{~F}}+2 I_{\mathrm{S}}\right) \\
& +\sum_{h=2}^{\infty} V_{\mathrm{L} h}\left(-I_{\mathrm{L} 1 h} \cos \phi_{\mathrm{L} 1 h}-I_{\mathrm{L} 2 h} \cos \phi_{\mathrm{L} 2 h}\right) .
\end{aligned}
$$

If the DC-capacitor voltage $v_{\mathrm{DC}}$ is kept constant by the CDCVC-based strategy for the three-leg PWM rectifier in Figure 1, the mean value of $\bar{p}_{\text {Rec }}$ should be the battery power $P_{\text {bat }}$ in (7). The mean value $\bar{p}_{\text {Rec }}$ is expressed as

$$
\bar{p}_{\text {Rec }}=P_{\text {bat }} .
$$

From (8) and (9), the RMS value $I_{S}$ in (5) is given by

$$
\begin{aligned}
I_{\mathrm{S}}= & \frac{I_{\mathrm{L} 1 \mathrm{~F}} \cos \phi_{\mathrm{L} 1 \mathrm{~F}}+I_{\mathrm{L} 2 \mathrm{~F}} \cos \phi_{\mathrm{L} 2 \mathrm{~F}}}{2} \\
& +\frac{\sum_{h=2}^{\infty} V_{\mathrm{L} h}\left(I_{\mathrm{L} 1 h} \cos \phi_{\mathrm{L} 1 h}+I_{\mathrm{L} 2 h} \cos \phi_{\mathrm{L} 2 h}\right)}{2 V_{\mathrm{LF}}}+\frac{P_{\mathrm{bat}}}{2 V_{\mathrm{LF}}} .
\end{aligned}
$$

Equation (10) demonstrates that the CDCVC-based strategy for the three-leg PWM rectifier in Figure 1 attains balanced and sinusoidal source currents at a unity power factor even though 
both source voltages and load currents are distorted. If the secondary-side voltages $v_{\mathrm{L} 1}$ and $v_{\mathrm{L} 2}$ are sinusoidal, as expressed by (2) in [24], the RMS value $I_{S}$ in (5) is expressed as

$$
I_{\mathrm{S}}=\frac{I_{\mathrm{L} 1 \mathrm{~F}} \cos \phi_{\mathrm{L} 1 \mathrm{~F}}+I_{\mathrm{L} 2 \mathrm{~F}} \cos \phi_{\mathrm{L} 2 \mathrm{~F}}}{2}+\frac{P_{\mathrm{bat}}}{2 V_{\mathrm{LF}}} .
$$

The RMS value $I_{S}$ is originated in the fundamental active components on the load side with $P_{\text {bat }} / 2 V_{\mathrm{LF}}$. Note that the RMS value $I_{S}$ in (10) is increased with the harmonic components, which is $\sum_{h=2}^{\infty} V_{\mathrm{L} h}\left(I_{\mathrm{L} 1 h} \cos \phi_{\mathrm{L} 1 h}+I_{\mathrm{L} 2 h} \cos \phi_{\mathrm{L} 2 h}\right) / 2 V_{\mathrm{LF}}$, as compared with $I_{\mathrm{S}}$ in (11). This demonstrates theoretically that the source-side fundamental active power is balanced with the load-side active power, which consists of the harmonic active power in addition to the fundamental active power, by the CDCVC-based strategy in Figure 1 and balances the active power between the source side and load side. However, the harmonic active components in (10) are much smaller than the fundamental components in the following simulation and experimental setup because the third-order component of $2.7 \%$, fifth-order component of $2.0 \%$, and seventh-order component of $1.2 \%$ are included in the primary-side voltage $v_{S}$ in Figure 1 . The BBC with the IGBTs also causes losses. Thus, balancing the active power between the source side and load side cannot be practically demonstrated. In the following simulation and experimental results, the active power balancing will not be demonstrated. It is also noted that the third-order, fifth-order, and seventh-order harmonics in the load currents $i_{\mathrm{L} 1}$ and $i_{\mathrm{L} 2}$ are increased by $2.7 \%, 2.0 \%$, and $1.2 \%$ as compared with those of the load currents $i_{\mathrm{L} 1}$ and $i_{\mathrm{L} 2}$ in the literature $[15,24]$. This means that the load currents waveforms $i_{\mathrm{L} 1}$ and $i_{\mathrm{L} 2}$ in the following simulation and experimental results are similar to those in $[15,24]$.

\section{Simulation Results}

The validity and high-practicability of the CDCVC-based harmonics compensation with the three-leg PWM rectifier in the BBC under distorted source-voltage and load-current conditions are confirmed by digital computer simulation using PSIM software. In single-phase three-wire distribution feeders, the unbalanced ratio (UR) is defined as

$$
\mathrm{UR}=\frac{S_{1}-S_{2}}{S_{\mathrm{A}} \times 0.5} \times 100 \%,
$$

where $S_{1}$ is the apparent power in Feeder1 and $S_{2}$ is the apparent power in Feeder2. $S_{\mathrm{A}}$ is the sum of apparent powers $S_{1}$ and $S_{2}$ in Feeder1 and Feeder2, respectively. The maximum UR is determined by Japanese guidelines [25]. According to the guidelines [25], the UR should be less than $40 \%$ for domestic power consumption. A Load1 of $1.2 \mathrm{pu}$ is connected in Feeder1, where the power factor is 0.87 , and the THD value is $23.7 \%$ in Figure 1 . A Load 2 of $0.8 \mathrm{pu}$ is connected in Feeder2, where the power factor is 0.90 , and the THD value is $20.9 \%$. Generally, the load conditions in Feeder1 and Feeder fluctuated greatly. In [26], the required-capacity of the three-leg PWM rectifier in the previously proposed BBC was discussed by digital computer simulation using PSIM software under several load conditions in Feeder1 and Feeder2. The simulation results demonstrated that the required-capacity of the three-leg PWM rectifier was maximum with Load1 of $1.2 \mathrm{pu}$ and Load2 of $0.8 \mathrm{pu}$. This means that the amplitudes of the output currents $i_{\mathrm{C} 1}, i_{\mathrm{C} 2}$, and $i_{\mathrm{C} 3}$ are maximum with Load1 of 1.2 pu and Load 2 of $0.8 \mathrm{pu}$. These load conditions are severe for the three-leg PWM rectifier. Thus, Load1 of $1.2 \mathrm{pu}$ and Load2 of $0.8 \mathrm{pu}$ are connected in Feeder1 and Feeder2 in the following simulation and experimental results.

Table 2 lists the circuit constants for Figure 1, which are used in the following simulation results. $K_{\mathrm{P}}=0.6, T_{\mathrm{I}}=30.0 \mathrm{~ms}$, and $T_{\mathrm{D}}=0.01 \mathrm{~ms}$ are used in the PID controller for the CDCVC. In PI controllers in $d-q$ coordinates for both the fundamental and third-order currents, $K_{\mathrm{P}}=0.06$ and $T_{\mathrm{I}}=8 \mathrm{~ms}$ are used. $K_{\mathrm{P}}=0.15$ and $T_{\mathrm{I}}=3 \mathrm{~ms}$ are used in the PI controller for the current feedback control of the bidirectional DC-DC converter. These values in controllers are determined with Ziegler-Nichols ultimate sensitivity method and then improved with a digital computer simulation. 
Table 2. Circuit constants for Figure 1.

\begin{tabular}{|c|c|c|c|}
\hline \multirow{2}{*}{ Item } & \multirow{2}{*}{ Symbol } & \multicolumn{2}{|c|}{ Value } \\
\hline & & Simulation & Experiment \\
\hline $\begin{array}{l}\text { Filter inductor for } \\
\text { three-leg pulse-width-modulated (PWM) rectifier }\end{array}$ & $L_{\mathrm{f} 1}$ & \multicolumn{2}{|c|}{$0.46 \mathrm{mH}$} \\
\hline $\begin{array}{l}\text { Filter capacitor for } \\
\text { three-leg PWM rectifier }\end{array}$ & $C_{\mathrm{f} 1}$ & \multicolumn{2}{|c|}{$10.4 \mu \mathrm{F}$} \\
\hline $\begin{array}{l}\text { Switching inductor for } \\
\text { three-leg PWM rectifier }\end{array}$ & $L_{\mathrm{S} 1}$ & \multicolumn{2}{|c|}{$1.0 \mathrm{mH}$} \\
\hline DC capacitor & $C_{\mathrm{DC}}$ & \multicolumn{2}{|c|}{$2700 \mu \mathrm{F}$} \\
\hline DC-capacitor voltage & $V_{\mathrm{DC}}^{*}$ & $385 \mathrm{Vdc}$ & $360 \mathrm{Vdc}$ \\
\hline $\begin{array}{l}\text { Switching inductor for } \\
\text { bidirectional DC-DC converter }\end{array}$ & $L_{\mathrm{S} 2}$ & \multicolumn{2}{|c|}{$4.4 \mathrm{mH}$} \\
\hline $\begin{array}{l}\text { Filter capacitor for } \\
\text { DC-DC converter }\end{array}$ & $C_{\mathrm{f} 2}$ & \multicolumn{2}{|c|}{$1000 \mu \mathrm{F}$} \\
\hline Battery voltage & $V_{\text {bat }}$ & $360 \mathrm{Vdc}$ & $257 \mathrm{Vdc}$ \\
\hline $\begin{array}{l}\text { Reference value for switching inductor current } \\
\text { of bidirectional DC-DC converter }\end{array}$ & $I_{\text {LS2 }}^{*}$ & 5 Adc & 4.29 Adc \\
\hline Internal resistance of battery & $r$ & \multicolumn{2}{|c|}{$72 \mathrm{~m} \Omega$} \\
\hline Switching frequency & $f_{\mathrm{SW}}$ & \multicolumn{2}{|c|}{$9.36 \mathrm{kHz}$} \\
\hline Dead time for each leg in PWM rectifier & $T_{\mathrm{d}}$ & \multicolumn{2}{|c|}{$3.5 \mu \mathrm{s}$} \\
\hline
\end{tabular}

Figure 2 shows the simulation results for Figure 1, where the proposed BBC charges the battery with the constant battery current control. $v_{\mathrm{S}}$ is the source voltage, and $v_{\mathrm{L} 1}$ and $v_{\mathrm{L} 2}$ are the secondary-side voltage waveforms; $i_{\mathrm{S} 1}$ and $i_{\mathrm{S} 2}$ are the secondary-side current waveforms; $i_{\mathrm{L} 1}$ and $i_{\mathrm{L} 2}$ are the load-side current waveforms of the domestic consumer. $i_{\mathrm{C} 1}, i_{\mathrm{C} 2}$, and $i_{\mathrm{C} 3}$ are the output current waveforms of the $\mathrm{BBC} ; v_{\mathrm{DC}}$ is the DC-capacitor voltage waveform; and $i_{\mathrm{LS} 2}$ is the switching inductor current waveform of the bidirectional DC-DC converter. The reference value $I_{\mathrm{LS} 2}^{*}$ for $i_{\mathrm{LS} 2}$ is -5 Adc, where the minus sign means that the bidirectional DC-DC converter charges the battery $V_{\text {bat }}$. The switching inductor current $i_{\mathrm{LS} 2}$ is well adjusted to the reference value $I_{\mathrm{LS} 2}^{*}$. The source currents $i_{\mathrm{S} 1}$ and $i_{\mathrm{S} 2}$ are balanced and sinusoidal at a unity power factor although the load currents $i_{\mathrm{L} 1}$ and $i_{\mathrm{L} 2}$ are unbalanced and heavily distorted, and the secondary-side voltages $v_{\mathrm{L} 1}$ and $v_{\mathrm{L} 2}$ are also distorted. The THD values of $i_{\mathrm{S} 1}$ and $i_{\mathrm{S} 2}$ are $2.0 \%$ and $1.9 \%$, respectively, and the voltage ripple of $v_{\mathrm{DC}}$ is $1.2 \%$. The simulation results of Figure 2 demonstrate that the proposed BBC of Figure 1 improve the power quality on the source side in single-phase three-wire distribution feeders charging the battery $V_{\text {bat }}$ in EVs.

Figure 3 shows the simulation results for Figure 1, where the proposed BBC discharges the battery with constant battery current control. The DC-DC converter discharges the battery $V_{\text {bat }}$ with the positive reference value $I_{\mathrm{LS} 2}^{*}$ of $5 \mathrm{Adc}$. The switching inductor current $i_{\mathrm{LS} 2}$ is also well controlled to the reference value $I_{\mathrm{LS} 2}^{*}$. The source currents $i_{\mathrm{S} 1}$ and $i_{\mathrm{S} 2}$ are also balanced and sinusoidal at a unity power factor. The THD values of $i_{\mathrm{S} 1}$ and $i_{\mathrm{S} 2}$ are $3.5 \%$ and $2.6 \%$, respectively, and the voltage ripple of $v_{\mathrm{DC}}$ is $1.2 \%$. The simulation results of Figure 3 also demonstrate that the proposed BBC of Figure 1 improve the power quality on the source side in single-phase three-wire distribution feeders discharging the battery $V_{\text {bat }}$ in EVs. 


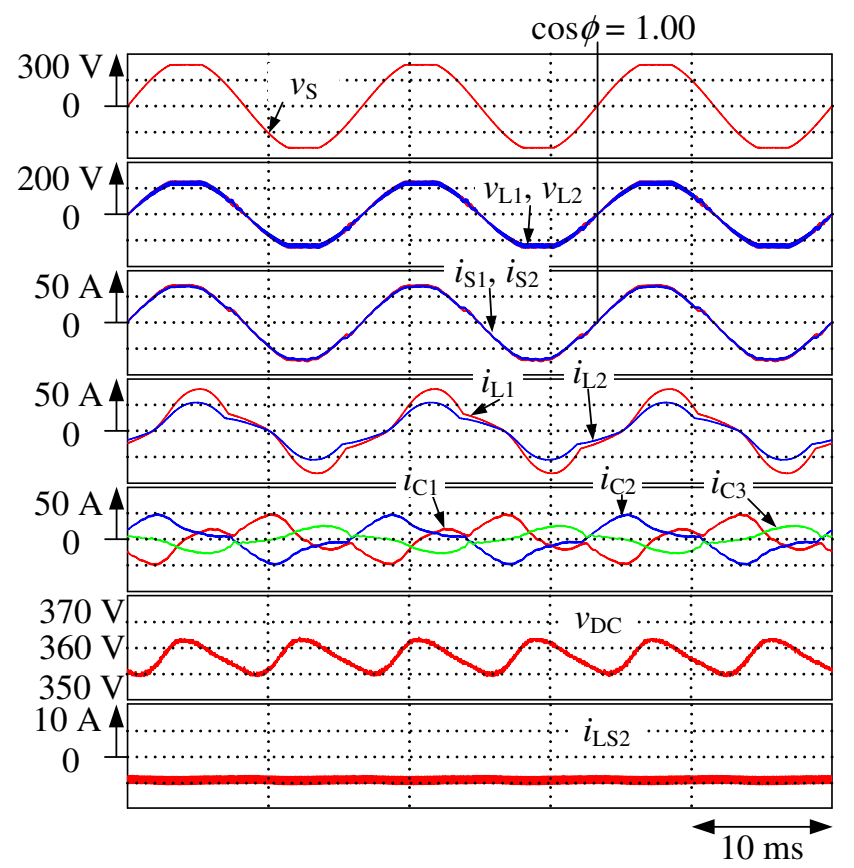

Figure 2. Simulation results for Figure 1 during battery-charging operation.

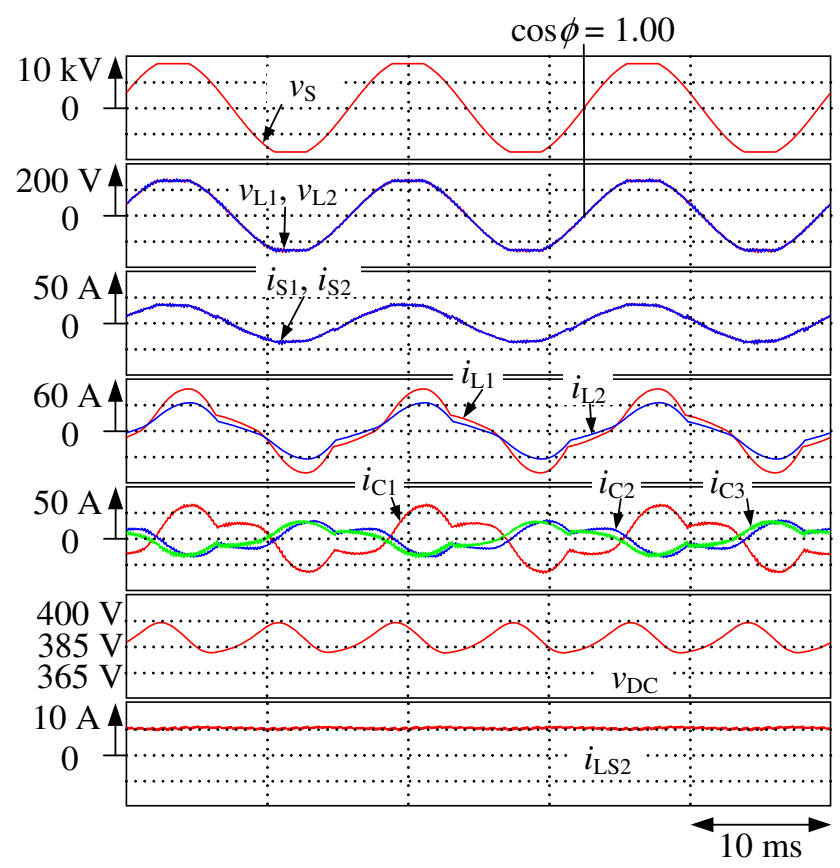

Figure 3. Simulation results for Figure 1 during battery-discharging operation.

When an owner drives an EV, the battery $V_{\text {bat }}$ is disconnected from the proposed BBC in Figure 1. Both $Q_{7}$ and $Q_{8}$ in the bidirectional DC-DC converter are off. The proposed BBC in Figure 1 acts as an active power-line conditioner in single-phase three-wire distribution feeders. Figure 4 shows the simulation results for Figure 1 without the battery $V_{\mathrm{bat}}$. The source currents $i_{\mathrm{S} 1}$ and $i_{\mathrm{S} 2}$ are balanced at a unity power factor. The THD values of $i_{\mathrm{S} 1}$ and $i_{\mathrm{S} 2}$ are $2.1 \%$ and $2.1 \%$, respectively, and the voltage ripple of $v_{\mathrm{DC}}$ is $1.2 \%$. The THD values of $i_{\mathrm{S} 1}$ and $i_{\mathrm{S} 2}$ in Figures 2-4 satisfy the regulations [19]. The proposed BBC can improve the power quality in single-phase three-wire distribution feeders even though the owner drives the EV. 


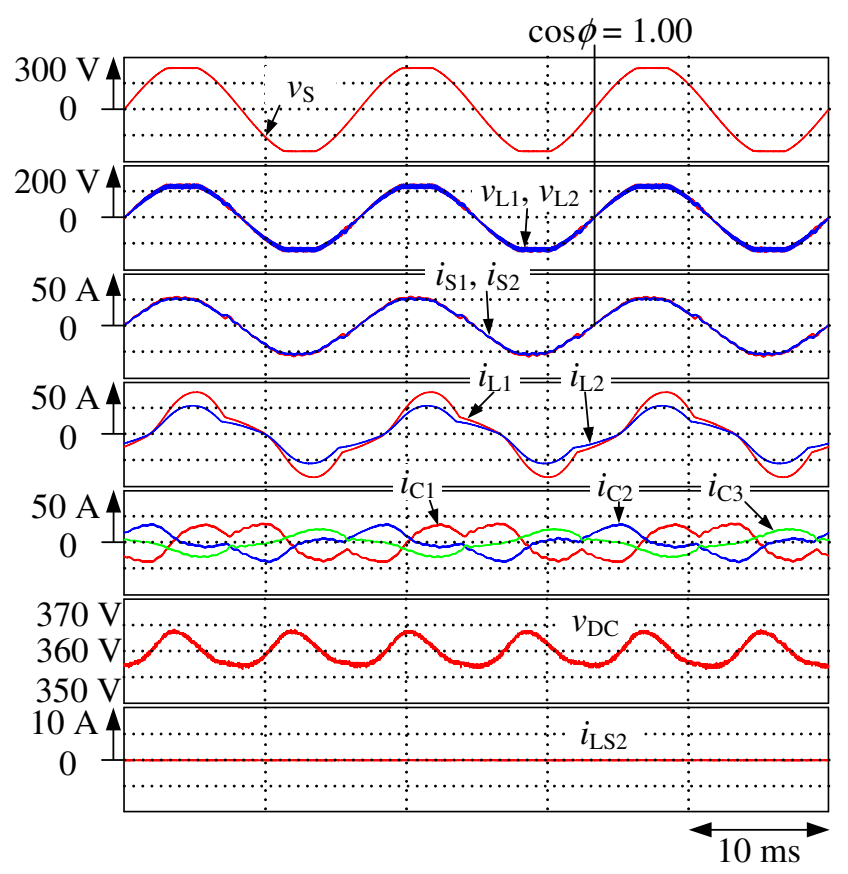

Figure 4. Simulation results for Figure 1 without battery, where BBC acts as active power-line conditioner.

Note that the THD values of $i_{S 1}$ and $i_{S 2}$ were worst during the battery-discharging operation because the amplitudes of $i_{\mathrm{S} 1}$ and $i_{\mathrm{S} 2}$ are minimized in the simulation results of Figures 2-4. In the literature [15], the THD values of $i_{\mathrm{S} 1}$ and $i_{\mathrm{S} 2}$ were $12.6 \%$ and $9.8 \%$, respectively, during the battery-discharging operation. The THD values of $i_{\mathrm{S} 1}$ and $i_{\mathrm{S} 2}$ are $3.5 \%$ and $2.6 \%$, respectively, shown in Figure 3 . The simulation results of Figures 2-4 demonstrate that the addition of current controllers for third-order harmonics greatly improves the THD values of the source currents $i_{S 1}$ and $i_{S 2}$ in single-phase three-wire distribution feeders.

\section{Experimental Results}

In Figure 1, the primary-side voltage is $6.6 \mathrm{kVrms}$. Thus, it is difficult to construct an experimental setup with the actual voltage rating of the distribution transformer for Figure 1 in the laboratory. Instead, a reduced-scale experimental setup is constructed and tested to demonstrate the validity and high-applicability of the CDCVC-based strategy of the BBC for EVs in single-phase three-wire distribution feeders. Figure 5 shows a block diagram of the constructed prototype experimental setup. The ratings of the distribution transformer are $180 \mathrm{Vrms}, 3.7 \mathrm{kVA}$, and $60 \mathrm{~Hz}$ on the primary side and 90 Vrms and 20.6 Arms on the secondary side. Table 3 shows test data for the distribution transformer in Figure 5. A programmable AC power source (NF ES-2000 Series) is connected on the primary side of the reduced-scale distribution transformer. A crest factor $(\mathrm{CF})$ is defined as

$$
\mathrm{CF}=\frac{\text { Amplitude of voltage waveform }}{\text { RMS value of voltage waveform }}
$$

Controlling the CF with the NF ES-2000 Series power source achieves the distorted source voltage $v_{\mathrm{S}}$. In Figure 5, the CF is 1.33 . The third-order component of $2.7 \%$, fifth-order component of $2.0 \%$, and seventh-order component of $1.2 \%$ are included in the primary-side voltage $v_{S}$ in Figure 5 . The THD value of the primary-side voltage $v_{\mathrm{S}}$ is $3.6 \%$. A Load1 of $1.2 \mathrm{pu}$ is connected to Feeder1, where the power factor is 0.87 and the THD value is $23.8 \%$. A Load2 of 0.8 pu is connected to Feeder2, where the power factor is 0.88 , the THD value is $24.1 \%$, and the UR given by (12) is $40 \%$. As shown in Figure $5 b$, a resistor $R$ of $60 \Omega$ is connected in parallel to the DC-capacitor $C_{\mathrm{f} 2}$ during the battery-charging operation. The connected resistor $R$ consumes the charged power, which is from the utility-grid. During the battery-discharging 
operation, a DC power supply (Takasago: HX0300-25) with an internal resistance $r$ of $72 \mathrm{~m} \Omega$ is connected to the DC-capacitor $C_{\mathrm{f} 2}$, where the output voltage of the $\mathrm{DC}$ power supply is $257 \mathrm{Vdc}$ because, as described before, the purpose of this paper is to demonstrate power quality compensation with the CDCVC-based strategy of the previously proposed BBC for electric vehicles in single-phase three-wire distribution feeders under distorted load-currents and source-voltage conditions. Figure 6 shows a picture of the constructed experimental setup for Figure 5. Using this experimental setup, the following experimental results are obtained. The circuit constants for Figure 5, which are used in the following experimental results, are also shown in Table 2.

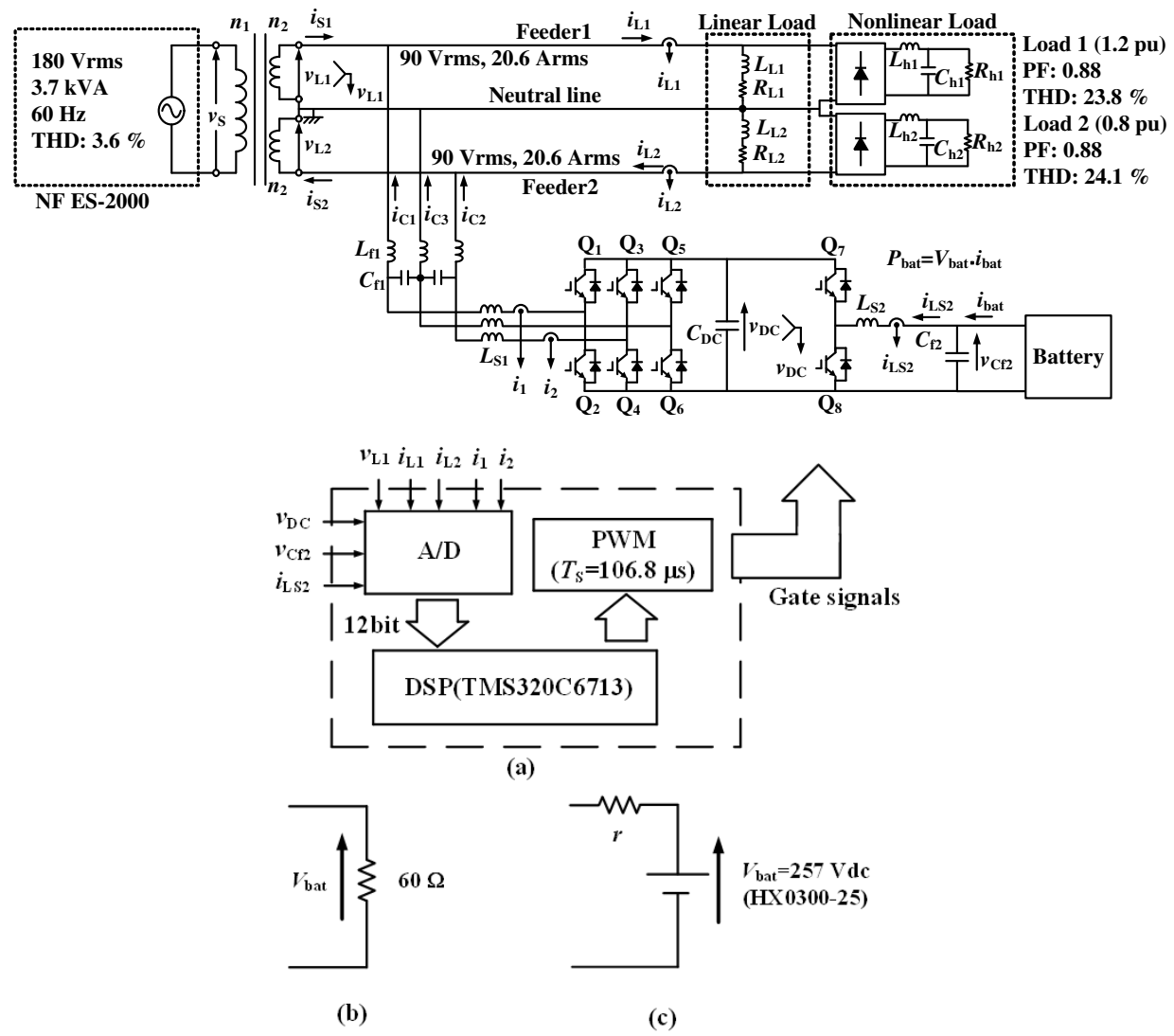

Figure 5. Block diagram of constructed experimental setup for BBC in Figure 1. (a) Power circuit and control block diagrams. (b) Battery model during battery-charging operation. (c) Battery model during battery-discharging operation

The secondary-side voltage $v_{\mathrm{L} 1}$, load currents $i_{\mathrm{L} 1}$ and $i_{\mathrm{L} 2}$, output currents $i_{1}$ and $i_{2}$, DC-capacitor voltage $v_{\mathrm{DC}}$, and inductor current $i_{\mathrm{LS} 2}$ are detected. These detected values are then fed into a digital signal processor (DSP) (TMS320C6713, $225 \mathrm{MHz}$ ) through 12-bit A/D converters. The sampling time $T_{\mathrm{S}}$ is $0.107 \mathrm{~ms}$. Thus, the switching frequency $f_{\mathrm{S}}$ is $9.36 \mathrm{kHz}$. This switching frequency achieves the current controllers in $d-q$ coordinates for the third-order harmonic components, which is perfectly synchronized with $v_{\mathrm{S}}$. The reference values $i_{1}^{*}, i_{2}^{*}$, and $i_{3}^{*}$ for the three-leg PWM rectifier are calculated by (1) in the DSP. The current controllers for both the fundamental and third-order harmonic currents are also carried out in the DSP. The circuit constants listed in Table 2 are used in Figure 5. $K_{\mathrm{P}}=0.6$, $T_{\mathrm{I}}=0.03 \mathrm{~s}$, and $T_{\mathrm{D}}=0.01 \mathrm{~ms}$ are used in the PI controller for the CDCVC-based strategy. $K_{\mathrm{P}}=0.06$ and $T_{\mathrm{I}}=8 \mathrm{~ms}$ are used in the PI controllers of the current feedback control in $d-q$ coordinates. $K_{\mathrm{P}}=0.15$ and $T_{\mathrm{I}}=3 \mathrm{~ms}$ are used in the PI controller of the current feedback control in the bidirectional DC-DC converter during both battery-charging and battery-discharging operations. 


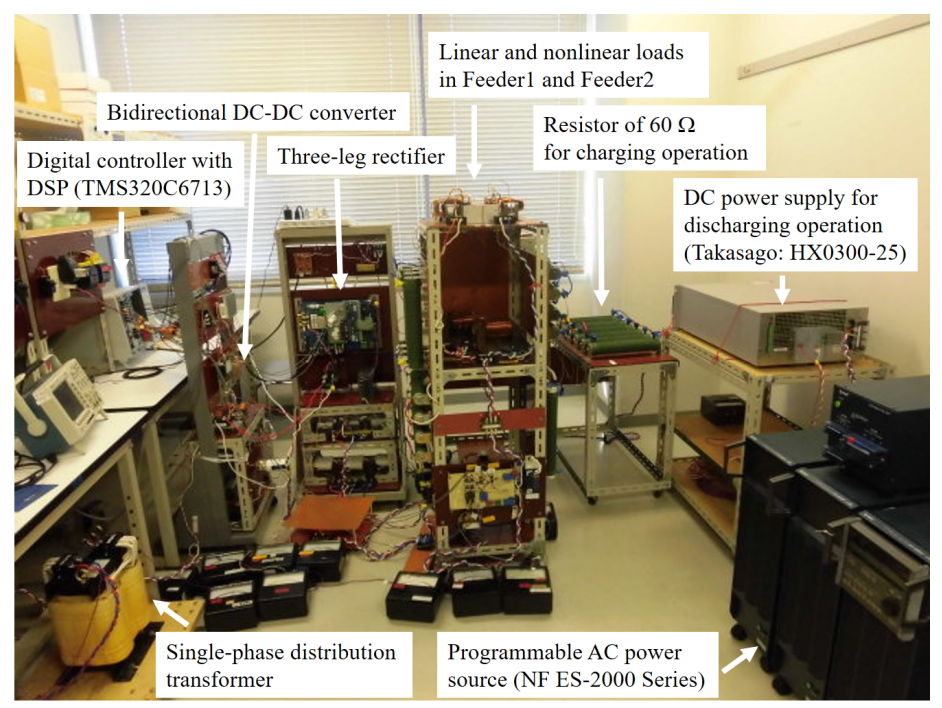

Figure 6. Real picture for constructed experimental setup of Figure 5.

Table 3. Test data for single-phase distribution transformer in Figure 1 on PSIM software.

\begin{tabular}{lccc}
\hline & Item & Symbol & Value \\
\hline & Rated voltage & $V_{\mathrm{r}}$ & $180 \mathrm{Vrms}$ \\
& Rated power & $S_{\mathrm{r}}$ & $3.7 \mathrm{kVA}$ \\
\hline \multirow{2}{*}{ Open circuit test } & Open circuit current & $I_{0}$ & $0.91 \mathrm{Arms}$ \\
& Open circuit power & $P_{0}$ & $30.8 \mathrm{~W}$ \\
\hline \multirow{2}{*}{ Short circuit test } & Short circuit voltage & $V_{\mathrm{S}}$ & $30.8 \mathrm{Vrms}$ \\
& Short circuit power & $P_{\mathrm{S}}$ & $95.6 \mathrm{~W}$ \\
\hline
\end{tabular}

The YOKOGAWA SL1000 High-Speed Data Acquisition Unit was used in the experiments, shown in Figure 6. The csv-formatted data is generated in the SL-1000 High-Speed Data Acquisition Unit. The following experimental waveforms were obtained importing the csv-formatted data to Excel.

Figure 7 shows the experimental results for Figure 5 during the battery-charging operation with constant battery current control. The resistor $R$ of $60 \Omega$ consumes the charged power from the utility-grid, as shown in Figure $5 \mathrm{~b} . v_{\mathrm{S}}$ is the source-voltage waveform, and $v_{\mathrm{L} 1}$ and $v_{\mathrm{L} 2}$ are the secondary-side-voltage waveforms; $i_{\mathrm{S} 1}$ and $i_{\mathrm{S} 2}$ are the secondary-side current waveforms; $i_{\mathrm{L} 1}$ and $i_{\mathrm{L} 2}$ are the load-side current waveforms of the domestic consumer; $i_{\mathrm{C} 1}, i_{\mathrm{C} 2}$, and $i_{\mathrm{C} 3}$ are the output current waveforms of the $\mathrm{BBC}$; $v_{\mathrm{DC}}$ is the DC-capacitor voltage waveform; and $i_{\mathrm{LS} 2}$ is the switching inductor current waveform of the bidirectional DC-DC converter. As shown in Table 2, the reference value $I_{\mathrm{LS} 2}^{*}$ for $i_{\mathrm{LS} 2}$ in the experimental setup is -4.29 Adc. As written in the simulation results, the minus sign means that the bidirectional DC-DC converter charges the battery $V_{\text {bat }}$. Note that the charged power, which is from the utility-grid, is consumed by the resistance $R$ of $60 \Omega$. The switching-inductor current $i_{\text {LS2 }}$ is well-adjusted to the reference value $I_{\mathrm{LS} 2}^{*}$. The source currents $i_{\mathrm{S} 1}$ and $i_{\mathrm{S} 2}$ are balanced and sinusoidal at a unity power factor, although the load currents $i_{\mathrm{L} 1}$ and $i_{\mathrm{L} 2}$ are unbalanced and heavily distorted and the secondary-side voltages $v_{\mathrm{L} 1}$ and $v_{\mathrm{L} 2}$ are distorted. The THD values of $i_{\mathrm{S} 1}$ and $i_{\mathrm{S} 2}$ are $4.1 \%$ and $3.1 \%$, respectively, and the voltage ripple of $v_{\mathrm{DC}}$ is $1.2 \%$. Figure 8 shows the experimental results for Figure 5, where the proposed BBC discharges the power from the battery $V_{\text {bat, }}$, which is the DC power supply (Takasago: HX0300-25) with a constant battery current control, as shown in Figure $5 \mathrm{c}$. The reference value $I_{\mathrm{LS} 2}^{*}$ for $i_{\mathrm{LS} 2}$ in the experimental setup is $4.29 \mathrm{Adc}$. The switching-inductor current $i_{\mathrm{LS} 2}$ is also well controlled to the reference value $I_{\mathrm{LS} 2}^{*}$. The source currents $i_{\mathrm{S} 1}$ and $i_{\mathrm{S} 2}$ are balanced and sinusoidal at a unity power factor. The THD values of $i_{\mathrm{S} 1}$ and $i_{\mathrm{S} 2}$ are $7.1 \%$ and $5.4 \%$, respectively, and the voltage ripple of $v_{\mathrm{DC}}$ is $1.7 \%$. The experimental results of Figures 7 and 8 demonstrate that the proposed BBC of Figure 1 
improve the power quality on the source side in single-phase three-wire distribution feeders charging or discharging the battery $V_{\text {bat }}$ in EVs.

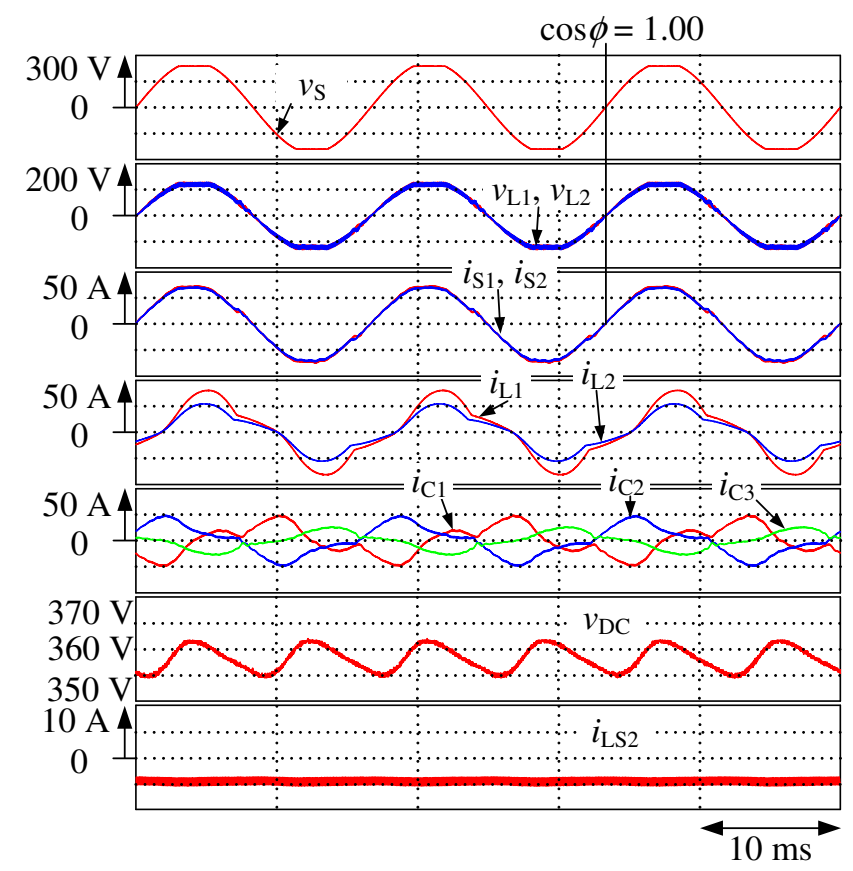

Figure 7. Experimental results for Figure 5 during battery-charging operation.

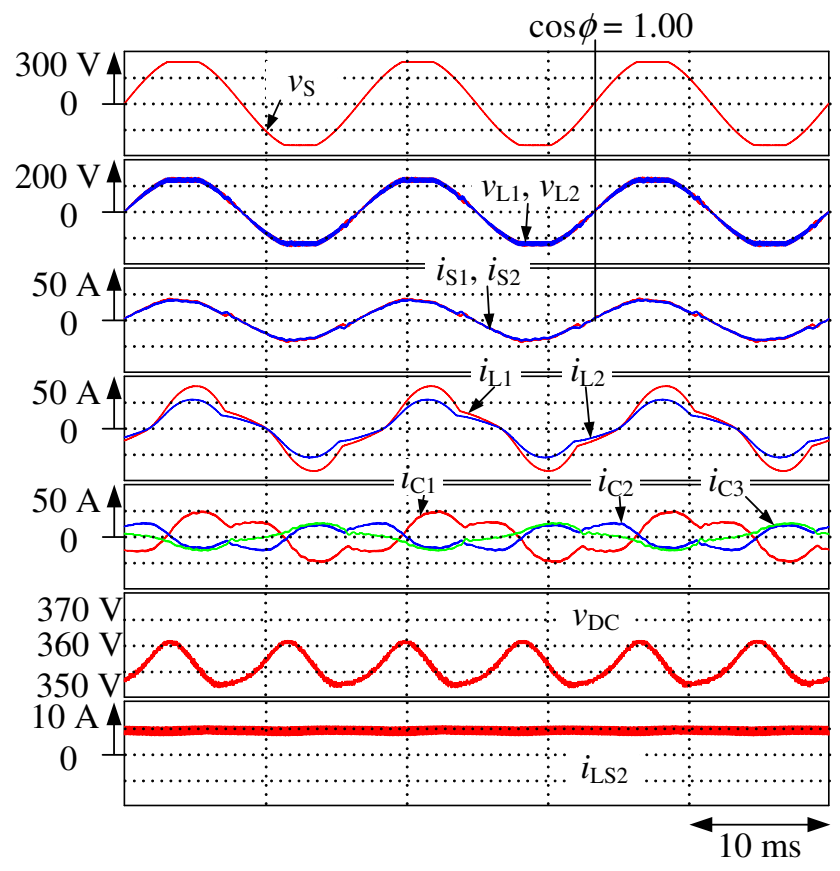

Figure 8. Experimental results for Figure 5 during battery-discharging operation.

Figure 9 shows the experimental results for Figure 5, where both the resistor $R$ and DC power supply are not connected to the capacitor $C_{\mathrm{f} 2}$, and where $\mathrm{Q}_{7}$ and $\mathrm{Q}_{8}$ in the bidirectional DC-DC converter are off. The proposed BBC performs as an active power-line conditioner in single-phase three-wire distribution feeders. The source currents $i_{\mathrm{S} 1}$ and $i_{\mathrm{S} 2}$ are balanced and sinusoidal at a unity power factor. The THD values of $i_{S 1}$ and $i_{S 2}$ are $5.3 \%$ and $4.1 \%$ respectively, and the voltage ripple of 
$v_{\mathrm{DC}}$ is $1.8 \%$. The experimental results of Figure 9 also demonstrate that the proposed BBC of Figure 1 can improve the power quality in single-phase three-wire distribution feeders even when the owner drives the EV.

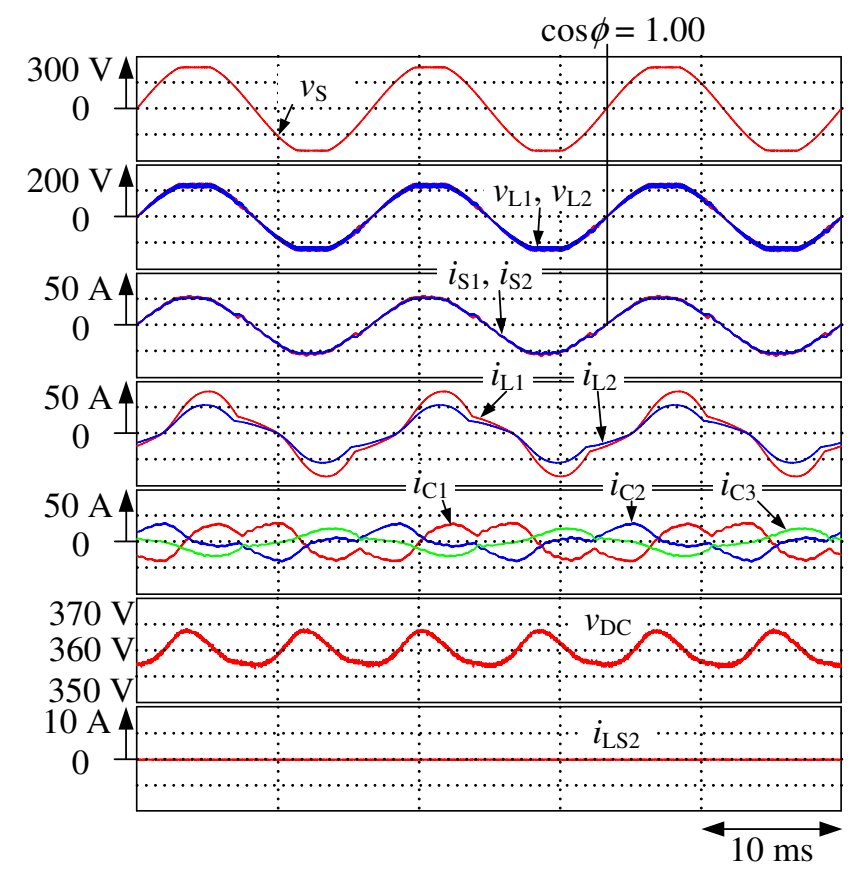

Figure 9. Experimental results for Figure 5 without battery, where BBC acts as an active power-line conditioner.

The THD values of $i_{\mathrm{S} 1}$ and $i_{\mathrm{S} 2}$ were $17.0 \%$ and $10.2 \%$ during the battery-discharging operation in the literature [15], while the THD values of $i_{\mathrm{S} 1}$ and $i_{\mathrm{S} 2}$ are $7.1 \%$ and $5.4 \%$, respectively. The experimental results of Figures 7-9 also demonstrate that the addition of current controllers for third-order harmonics greatly improves the THD values of the source currents $i_{\mathrm{S} 1}$ and $i_{\mathrm{S} 2}$ in Figure 1 . The experimental results of Figures 7-9 well agree with the simulation results of Figures 2-4, respectively. This demonstrates that the experimental results of Figures 7-9 with the reduced-scale experimental setup of Figure 5 are valid.

\section{Conclusions}

This paper addressed power quality compensation of the previously proposed BBC with a CDCVC-based strategy for EVs in single-phase three-wire distribution feeders under distorted source-voltage and load-current conditions. The instantaneous power flowing into the three-leg PWM rectifier in the BBC was discussed. Instantaneous power flow demonstrated that the CDCVC-based strategy attains the balanced and sinusoidal source currents at a unity power factor even though both the source voltage and load currents are distorted. The validity and high-practicability of the previously proposed CDCVC-based strategy for the BBC under distorted source-voltage and load-current conditions were confirmed by a digital computer simulation using PSIM software. A reduced-scale prototype experimental model was constructed and tested. Simulation and experimental results demonstrated that balanced and sinusoidal source currents at a unity power factor are achieved on the secondary side of the distribution transformer during both battery-charging and -discharging operations in EVs even though both the source voltage and load currents are distorted.

Author Contributions: Conceptualization and methodology, F.I.; simulation, F.I., K.N. and Y.O.; validation, I.F., K.N., Y.O., H.Y., T.T. and M.O.; data curation, K.N. and Y.O.; writing-original draft preparation, F.I.; writing-review and editing, H.Y., M.O., and T.T.; visualization, F.I. and K.N.; supervision, T.T.; project 
administration, H.Y. and T.T.; funding acquisition, T.T. All authors have read and agreed to the published version of the manuscript.

Funding: This research was funded by JSPS KAKENHI under Grant 16K06225.

Conflicts of Interest: The authors declare no conflict of interest.

\section{References}

1. Mitani, Y. Method and System for Leveling Power Load. Japan Patent 4862153 (P4 862 153), 25 January 2012.

2. Available online: http://www.nissan-global/com/JP/NEWS/ (accessed on 10 January 2012).

3. Yilmaz, M.; Krein, P.T. Review of benefits and challenges of vehicle-to-grid technology. In Proceedings of the IEEE Energy Conversion Congress and Exposition (ECCE), Raleigh, NC, USA, 15-20 September 2012; pp. 3082-3089.

4. Cvetkovic, I.; Thacker, T.; Dong, D.; Francis, G.; Podosinov, V.; Boroyevich, D.; Wang, F.; Burgos, R.; Skutt, G.; Lesko, J. Future home uninterruptible renewable energy system with vehicle-to-grid technology. In Proceedings of the IEEE Energy Conversion Congress and Exposition (ECCE), San Jose, CA, USA, 20-24 September 2009; pp. 2675-2681.

5. Hsu, Y.C.; Kao, S.C.; Ho, C.Y.; Jhou, P.H.; Lu, M.Z.; Liaw, C.M. On an electric scooter with G2V/V2H/V2G and energy harvesting functions. IEEE Trans. Power Electron. 2018, 33, 6910-6925. [CrossRef]

6. Cheng, H.; Chen, H.; Wang, Q. An integrated drive power converter topology for plug-in hybrid electric vehicle with G2V, V2G and V2H functions. In Proceedings of the 2019 22nd International Conference on Electrical Machines and Systems (ICEMS), Harbin, China, 11-14 August 2019; 6p.

7. Nasr, M.; Gupta, K.; da Silva, C.; Amon, C.H.; Trescases, O. SiC based on-board EV power-hub with high-efficiency DC transfer mode through AC port for vehicle-to-vehicle charging. In Proceedings of the 2018 IEEE Applied Power Electronics Conference and Exposition (APEC), San Antonio, TX, USA, 4-8 March 2018; pp. 3398-3404.

8. Akagi, H.; Kanazawa, Y.; Nabae, A. Instantaneous reactive power compensators comprising switching devices without energy storage components. IEEE Trans. Ind. Appl. 1984, 20, 625-630. [CrossRef]

9. Kisacikoglu, M.C.; Ozpineci, B.; Tolbert, L.M. Examination of a PHEV bidirectional charger system for V2G reactive power compensation. In Proceedings of the 2010 Twenty-Fifth Annual IEEE Applied Power Electronics Conference and Exposition (APEC), Palm Springs, CA, USA, 21-25 February 2010; pp. 458-465.

10. Kisacikoglu, M.C.; Ozpineci, B.; Tolbert, L.M. Reactive power operation analysis of a single-phase EV/PHEV bidirectional battery charger. In Proceedings of the 8th International Conference on Power Electronics-ECCE Asia, Jeju, Korea, 30 May-3 June 2011; pp. 585-591.

11. Monteiro, V.; Pinto, J.G.; Exposto, B.; Goncalves, H.; Ferreira, J.C.; Couto, C.; Afonso, J.L. Assessment of a battery charger for electric vehicles with reactive power control. In Proceedings of the 38th Annual Conference on IEEE Industrial Electronics Society, Montreal, QC, Canada, 25-28 October 2012; pp. 5124-51290.

12. Kisacikoglu, M.C.; Kesler, M.; Tolbert, L.M. Single-Phase On-Board Bidirectional PEV Charger for V2G Reactive Power Operation. IEEE Trans. Smart Grid 2015, 6, 767-775. [CrossRef]

13. Buja, G.; Bertoluzzo, M.; Fontana, C. Reactive Power Compensation Capabilities of V2G-Enabled Electric Vehicles. IEEE Trans. Power Electron. 2017, 32, 9447-9460. [CrossRef]

14. Tanaka, T.; Sekiya, T.; Tanaka, H.; Hiraki, E.; Okamoto, M. Smart charger for electric vehicles with power quality compensator on single-phase three-wire distribution feeders. IEEE Trans. Ind. Appl. 2013, 49, 2628-2635. [CrossRef]

15. Ikeda, F.; Tanaka, T.; Yamada, H.; Okamoto, M. Simple harmonics compensation method for smart charger with constant DC-capacitor voltage-control for electric vehicles in single-phase three-wire distribution feeders. IEEJ J. Ind. Appl. 2019, 8, 23-32. [CrossRef]

16. Blanco, A.M.; Yanchenko, S.; Meyer, J.; Schegner, P. The impact of supply voltage distortion on the harmonic current emission of non-linear loads. Dyna 2015, 82, 150-159. [CrossRef]

17. IEC 61000-4-13, Electromagnetic Compatibility (EMC)_Part 4-13: Testing and Measurement Techniques_-Harmonics and Interharmonics Including Mains Signalling at A.C. Power Port, Low Frequency Immunity Test; IEC: Geneva, Switzerland, 2015.

18. IEEE Standard 519-2014, Recommended Practices and Requirements for Harmonic Control in Electrical Power System; IEEE: New York, NY, USA, 2014. 
19. IEC61000-3-4, Electromagnetic Compatibility (EMC). Limits. Limitation of Emission of Harmonic Currents in Low-Voltage Power Supply Systems for Equipment with Rated Current Greater Than 16 A; IEC: Geneva, Switzerland, 1998.

20. Tarafdar Haque, M. Single-phase pq theory for active filters. In Proceedings of the 2002 IEEE Region 10 Conference on Computers, Communications, Control and Power Engineering, Beijing, China, 28-31 October 2002; Volume 3, pp. 1941-1944.

21. Arruda, L.N.; Silva, S.M. BJC Filho, “PLL structures for utility connected systems. In Proceedings of the Conference Record of IEEE-IAS Annual Meeting, Chicago, IL, USA, 30 September-4 October 2001; pp. 2655-2660.

22. Silva, S.M.; Lopes, B.M.; Filho, B.J.C.; Campana, R.P.; Boaventura, W.C. Performance evaluation of PLL algorithms for single-phase grid-connected systems. In Proceedings of the Conference Record of IEEE-IAS Annual Meeting, Seattle, WA, USA, 3-7 October 2004; pp. 2259-2263.

23. Zhang, R.S. Control of Single-Phase Power Converter in D-Q Coordinates. U.S. Patent, No. 6,621,252, 16 September 2003.

24. Nishikawa, K.; Ikeda, F.; Yamada, H.; Tanaka, T.; Okamoto, M. Improvement in harmonic compensation of a smart charger with a constant DC-capacitor voltage-control-based strategy for electric vehicles in single-phase three-wire distribution feeders. Energies 2018, 11, 1604. [CrossRef]

25. Japan Electric Association. Indoor Wiring Guidelines; JESC E0005; Japan Electric Association: Tokyo, Japan, 2005; p. 32. (In Japanese)

26. Tanaka, H.; Ikeda, F.; Tanaka, T.; Yamada, H.; Okamoto, M. Novel reactive power control strategy based on constant DC-capacitor voltage control for reducing the capacity of smart charger for electric vehicles on single-phase three-wire distribution feeders. IEEE J. Emerg. Sel. Top. Power Electron. 2016, 4, 481-488. [CrossRef]

(C) 2020 by the authors. Licensee MDPI, Basel, Switzerland. This article is an open access article distributed under the terms and conditions of the Creative Commons Attribution (CC BY) license (http:/ / creativecommons.org/licenses/by/4.0/). 